\title{
LA EVOLUCIÓN DE LOS ÁMBITOS FUNERARIOS: DE SAN ISIDORO DE LEÓN AL MONASTERIO DE LAS HUELGAS
}

\author{
Carmen Morais Puche ${ }^{l}$
}

\section{RESUMEN}

En este trabajo se ha intentado poner de relieve la evolución de los espacios funerarios en la Edad Media. Con ello hemos podido observar una especie de devenir cíclico, ya que tras la prohibición de enterrar los cuerpos en el interior de las iglesias se pasa a un momento en el que los enterramientos notables, a diferencia del resto, se ubicaban en lugares próximos al interior, tal es el caso de pórticos, galileas... Para a partir de ahí volver, poco a poco, a introducir los enterramientos en el interior de los templos.

Palabras Clave: Pórtico, Galilea, Panteón, enterramientos, planimetría, naves.

\section{ABSTRACT}

In this work we have tried to emphasize the evolution of funeral spaces in Middle Ages. With it we have been able to observed a kind of cyclical development, since after the prohibition of burying the bodies inside the churches we get to a moment in which the notable burials, unlike the rest, were located in places next to the interior, such it is the case of porticos, Galileas... For from there returning to introduce, little by little, the burials inside the temples.

Key Words: Portico, Galilea, Pantheon, burials, planimetry, naves.

La creación de ámbitos funerarios en la Edad Media para el enterramiento tanto para los reyes y su familia, como para los altos estamentos de la sociedad, incidirá con gran importancia en la modificación de la planimetría de iglesias anteriormente edificadas con la construcción de nuevos espacios. O bien se crearán nuevas tipologías en las que se dispondrán de una manera determinada y regularizada los espacios funerarios.

\footnotetext{
$1 \quad$ Email: cmoraisp@gmail.com.
} 
Podemos distinguir, según el profesor $\mathrm{Bango}^{2}$, dos grandes periodos. El primero abarcaría del siglo VI al XI, durante estos siglos, al estar prohibido enterrarse en el interior de las iglesias se eligen para los enterramientos de los personajes notables aquellos espacios con importancia reseñable en cuanto a la circulación de los fieles o en comunicación con el interior del templo (enfatizando así el espacio y otorgando mayor prestigio a los difuntos allí enterrados); el otro periodo abarcaría del siglo XII al XV. En este momento se permitirán ya los enterramientos en el interior del templo, lo que conlleva graves problemas espaciales en cuanto a la planimetría templaria ya que bien se transforman los espacios originales, o bien se crean nuevas tipologías.

Por otro lado, los lugares preferidos para los enterramientos reales durante los siglos XII y XIII estuvieron en el interior de las iglesias y claustros de las fundaciones monasteriales. Mientras que las restricciones habían sido realizadas para los enterramientos dentro del ámbito de las iglesias y catedrales, los privilegios papales permitían a las órdenes religiosas aceptar cuerpos laicos en sus monasterios. Los benedictinos serían los primeros beneficiarios de este privilegio, seguidos por los cistercienses, de esta manera dichas instituciones, durante el siglo XII, serían designadas como panteones familiares desde su fundación, tal es el caso de las Huelgas.

Retomando el primer periodo, dentro de los ámbitos de aquellos espacios de importancia reseñable, cabe destacar la relevancia del pórtico, espacio que al situarse próximo a la entrada del templo ofrecía una doble lectura para los poderosos: la proximidad a las Puertas del Paraíso, y la satisfacción ante la contemplación del enterramiento por todos aquellos fieles que acudiesen a la iglesia. Otro espacio entre cuya multitud de funciones se encontraba la de albergar enterramientos de notables son los pórticos laterales de los templos altomedievales, así como las galileas, cuya función litúrgica es preeminente, aunque debemos considerar también la funeraria, ya que al igual que el atrio, supone un lugar privilegiado de sepultura, en el cual se enterrarán los más notables de la sociedad. En algunos casos en este espacio se llegan a construir auténticos panteones familiares o de determinadas clases sociales. Su uso se llega a prolongar en el tiempo, incluso cuando ya podían utilizar el interior del templo para sus sepulturas.

Pese a que dentro de la tradición hispana la práctica más usual era situar los enterramientos de los privilegiados en los pórticos occidentales, durante el siglo XI y principios del XII los reyes y condes soberanos van a utilizar las galileas como ámbitos funerarios de gran prestigio. En la corona de Castilla y León los monasterios elegidos para situar tales ámbitos funerarios son los primeros que adoptaron la reforma cluniacense, situándose todos ellos en la zona de Tierra de Campos. Esta práctica dará lugar a la constitución de importantes cementerios reales o condales.

En el ambiente monástico del Reino de Aragón en el siglo XI encontramos también una serie de templos que asimilarán estos espacios funerarios, ejemplo de ello serán San Vicente de Cardona, San Pedro de Roda, Santa María de Ripoll y la Catedral de Barcelona.

Por otro lado, de todos estos espacios cabría destacar la creación de panteones regios, entre los que debemos hacer alusión al de Santa María de Oviedo, obra de Alfonso II, y

2 Bango Torviso, I. "El espacio para enterramientos privilegiados en la arquitectura medieval española”, Anuario del Departamento de Historia y Teoría del Arte 4 (1992), p. 93. 
el San Juan (que después cambiará su advocación por la de San Isidoro de León), cuyo cementerio Real es una réplica del anterior.

La iglesia de San Juan Bautista de León fue reformada por Fernando I, el cual manda también trasladar desde Sevilla las reliquias de San Isidoro, cambiando de esta manera la advocación del templo. Este rey, descendiente de Sancho el Mayor de Navarra debía ser enterrado en el monasterio de Oña, no obstante decidirá ser enterrado en Arlanza, decisión que será cambiada tras ser convencido por su esposa, la reina Sancha para ser enterrado en el panteón ubicado en el monasterio de San Juan (San Isidoro).

El panteón de San Isidoro (Fig. 1) plantea dos grandes problemas, su atribución, y su datación, teniendo hasta ahora tres hipótesis en boga entre los investigadores.

La primera de ellas defiende la construcción tanto de la nueva iglesia como del panteón durante el reinado de Fernando I, datándolo entre 1054 y 1067, utilizando como base para ello una inscripción, situada en uno de los pilares del porche del panteón, que reza: "Sancia regina Deo dicata peregit". Esto hace suponer que por lo menos la construcción ya había comenzado en 1067, fecha de la muerte de Sancha. Otro punto que apoyaría esta tesis es el siguiente fragmento extraído de la Historia Silense:

"Interrea, dominis regis coloqium Sancia regina petens, ei in sepulturam regué ecclesiam fieri legione persuadet, uby et eorumden corpora iuste magnificeque hamari debeant. Decreverat namque Fernandus rex, vel Onie, quem locum carum semper habebat, siue in ecclesia beati Petri de Aslanza corpus suum sepultare tradere porro Sancia regina, quoniam in legionensi regué cementerio pater suus dine memorie Adefonsus princeps et eius frater Veremudus serenissimus rex in Christo quiescebant, ut quoque et ipsa et eiusdem vir cum eis post mortem quiescerent, pro viribus laborat. Rex igitur petición fidissime coningis annuens, depuntatur cementarii, qui assidue operam dent tam dignissimo labori" ${ }^{3}$.

Otra de las hipótesis señala que la artífice debió de ser Urraca, hija de Fernando I, la que mandó levantar el panteón tal y como ha llegado hasta nuestros días. Esta hipótesis se sustenta en la interpretación de una inscripción del epitafio de Urraca, en el que se puede leer: "Haec ampliavit ecclesiam Istam"4.

Y la última hipótesis hace referencia a la iglesia reconstruida por Fernando I, así como la obra del panteón, y una posterior ampliación llevada a cabo por la Infanta Doña Urraca.

Un ejemplo que el profesor Bango trae a colación en relación a toda esta polémica es el de San Pedro de Taverga en Asturias (Fig. 2) construido a imitación de San Isidoro 5 (Fig. 3). En él vemos cómo hay una primera construcción en la que podemos observar cómo sus muros fueron cortados para servir de apoyo a la nueva iglesia románica que se construiría

3 Este texto pondría en relación directa de las obras a Sancha y a Fernando I, corroborando dicha hipótesis, defendida por investigadores como el padre Viñayo.

4 Aquí los investigadores que defienden esta tesis han querido interpretar "ampliavit" como la ampliación de la iglesia que sus padres rehicieron, así como la construcción del cementerio real.

5 Senra, J. L “Aproximación a los espacios litúrgico-funerarios en Castilla y León: pórticos y galileas”, Gesta, XXXVI/2 (1997), p.126 y ss. 
sobre ella. Esto mismo ocurre en San Isidoro, cuya estructura prerrománica condiciona a la construcción románica. ${ }^{6}$

Tradicionalmente la estructura del panteón se había puesto en relación con el mundo carolingio, más concretamente con tipologías de torre-pórtico, así como su paralelismo con Saint-Benoît-sur-Loire o Saint-Hilaire de Poitiers ${ }^{7}$, donde podemos ver espacios de transición abiertos al exterior por tres de sus caras, y con amplias arcadas.

Sin embargo, el profesor Bango a lo largo de sus investigaciones ha llegado a la conclusión de que el panteón presenta un planteamiento que entronca con las fórmulas hispánicas, aunque con un léxico ya plenamente románico ${ }^{8}$. Es decir, nos encontramos con un contra ábside a los pies de la iglesia, creando así un espacio "autónomo" aunque a su vez se encuentra íntimamente ligado al interior de la iglesia ${ }^{9}$, sin embargo este ámbito funerario quedaba aislado de la nave central con un muro el cual únicamente tenía una puerta por la que comunicarse con el interior del templo, dando así lugar a un "habitatio sepulchri"10 (Fig. 4 y 5)

Por otro lado, siguiendo el estudio de la evolución de los ámbitos funerarios en este mismo ámbito territorial, podemos aventurarnos a decir que son las fundaciones monasteriales relacionadas con Cluny las que han asumido esta estructura. Todas ellas las encontramos en la zona llamada Tierra de Campos, en la cual Senra sitúa el epicentro de los dominios cluniacenses en la Península Ibérica. ${ }^{11}$ De entre ellas podemos destacar San Martín de Frómista, San Isidoro de Dueñas, el monasterio de Sahagún (Fig. 6) y San Zoilo de Carrión de los Condes (Fig. 7). A través de estos ejemplos podemos observar cómo en las últimas décadas del siglo XI se "ensamblan" dos corrientes, por un lado una tradición local que sigue el esquema tradicional de los enterramientos privilegiados occidentales; y por otro lado, una vertiente traída por los monjes cluniacenses, en la que se suma una función litúrgica a la proyección de un piso alto (buscando de esta manera una apertura al exterior).

En cuanto al monasterio de Sahagún, en el pórtico occidental de la capilla de San Mancio se encuentran los enterramientos de los miembros más destacados de la corte de Alfon-

\footnotetext{
6 Lo que da lugar a una solución que el profesor Bango ha acuñado como "híbrida" en su obra El Arte románico en Castilla y León, Madrid, 1997.

7 Será Gómez Moreno el que realice por primera vez esta teoría, pero desestimando la influencia del templo de Saint-Benoît por considerarlo posterior en el tiempo. Gómez Moreno, M. Catálogo monumental de España. Provincia de León, Madrid, 1925, p. 182. en la actualidad esta teoría es seguida y aceptada por investigadores como Fernando Galtier (Galtier, F. "Le corps occidental des églises dans l'art roman espagnol du XI siecle: problèmes de recepción d'un modèle septentrional”, CCM, XXXIV, 1991, p.305) y Durliat (Durliat, M., Espagne Romane, Paris 1993, p.94)

8 En esta interpretación del panteón nos encontramos también con la teoría de Díaz Jiménez, quien rechazó considerar el panteón como un nártex, ya que "el muro de cercamiento por el ocaso se halla adosado al lienzo de la antigua muralla, que el acceso por la parte del claustro se encuentra abrazado por los anchos zócalos que de éste le separan, y que desde luego debió ser construido para panteón lo patentizan los cuatro arcos entrantes que hay en sus muros no ligados con armadura y destinados, tal vez, para colocar bajo ellos las unas sepulcrales" Díaz Jiménez, J., "San Isidoro de León “, Boletín de la Sociedad Española de Excursiones, Madrid, 1997, p. 94.

9 Se adapta así el espacio a las disposiciones del concilio de Bracarense del siglo VI, mediante el cual quedaba prohibido el enterramiento en el interior de los templos.

10 Bango Torviso, I., "Arte prerrománico hispano. El arte en la España cristiana de los siglos VI al XI", en Summa Artis. Historia General del Arte, vol. VIII-II, Madrid, 2001, p. 89.

11 Senra, J. L, "Aproximación a los espacios litúrgico-funerarios en Castilla y León: pórticos y galileas", Gesta, XXXVI/2 (1997), p. 130.
} 
so VI, entre los que podemos señalar al hijo de Pedro Ansúrez (+ 1093), y al propio Pedro Ansúrez (+ 1109) junto con sus esposas, el cual será trasladado en el siglo XIII al interior del nuevo templo. Éste en 1080 ya había dejado patente su deseo de ser allí enterrado ${ }^{12}$. La planta sigue los parámetros de la del panteón real de San Isidoro de León, estando claramente desplazado el eje respecto a la iglesia. Se trata de una construcción cuadrangular que en su interior posee una entrada descentrada que da paso al templo, aunque con una particularidad, el acodillamiento de las columnas no se realiza hacia la capilla, sino hacia la iglesia. Esto podría estar fundamentado en el gusto por enfatizar el ámbito funerario, dotándolo así de una importancia preeminente.

Esta estructura con función claramente funeraria hace que nos planteemos los puntos en común y las "discrepancias" que tiene con el panteón de San Isidoro, a parte, claro está de las diferencias de tamaño. Pese a que ambas edificaciones poseen la misma tipología y el mismo papel funcional, la diferencia principal la podemos hallar en la apertura hacia el exterior del panteón de Sahagún. Así mismo podemos ver un ejemplo de cómo los notables copiaban estructuras regias para así dotar de mayor consideración a su propio ámbito funerario.

Por otro lado, dentro también de esta misma área geográfica, nos encontramos con una serie de templos insertos plenamente en el ámbito y las demarcaciones cluniacenses que según Senra "a priori, pudieran haber compartido un a homogeneidad tipológica" ", tal es el caso de San Zoilo de Carrión, San Isidoro de Dueñas y San Martín de Frómista.

La obra de San Zoilo de Carrión fue promovida por el Conde Gómez Díaz, y rematada por su esposa. El Conde será aquí enterrado en el año 1057, y entregado a la congregación de Cluny en 1076. Aquí recibirán sepultura todos los Infantes y Señores de Carrión así como sus descendientes. Senra se basará en el resultado de las excavaciones arqueológicas realizadas para fundamentar su hipótesis que remarca la similitud del trazado de este edificio con el de San Isidoro de León, planificando también un panteón similar al de la iglesia fernandina. Dicho planteamiento, según este autor, puede quedar también fundamentado en dos edificios que más adelante veremos: San Isidoro de Dueñas y San Martín de Frómista.

San Isidoro de Dueñas, será el primer priorato cluniacense de la corona de Castilla y León, datándose en el año 1073.

Tanto en San Zoilo como Sahagún y Oña nos topamos con unas estructuras que se corresponde con la de las galileas. Mientras que San Zolio servirá a modo de panteón condal en los dos otros ejemplos nos encontramos con enterramientos regios.

Retomando el caso de San Zolio de Carrión, será Yepes el que recoja el conocimiento de este ámbito funerario con las siguientes palabras:

"A los pies de la iglesia de San Zoil, que dice Morales que no era capilla y que antiguamente tenía nombre de Galilea, ahora se llama capilla de los condes y está dedicada a San Juan, que fue el principio de aquel monasterio, y se ven en ella,

12 Esta práctica era bastante común tanto en el caso de los nobles como de los reyes.

13 Senra, J.L., "Aproximación a los espacios litúrgico-funerarios en Castilla y León: pórticos y galileas", Gesta, XXXVI/2 (1997), p. 131. 
decentemente puestos, los entierros del conde y sus hijos, con inscripciones y versos antiquísimos...En esta capilla no se podía enterrar sino personas muy principales." 14

En San Salvador de Oña nos encontramos también ante un importante ámbito funerario en el que encontramos enterramientos de condes y algunos reyes ${ }^{15}$, los cuales se situaron concretamente en un pórtico que podemos identificar con una galilea. Pese a que en siglo XI durante el reinado de Alfonso VII (1137) se intentaron trasladar los restos al interior de la iglesia, ello no se llevaría a cabo hasta el siglo XII, bajo el reinado de Sancho IV. La configuración de la galilea de Oña tuvo lugar bajo la tutela de una orden monástica que seguía los principios de la reforma cluniacense.

En el caso del monasterio de San Facundo y San Primitivo de Sahagún (Fig. 8) nos encontramos también una importante fundación cluniacense, en la cual se permitirá la construcción de otra galilea a los pies de la iglesia que serviría de ámbito funerario de Alfonso VI y sus esposas. Será Sancho IV el que en el siglo XII introduzca los cuerpos de sus antepasados en la iglesia. Esta actitud remite a la idea presente en esa época de considerar indigno el enterramiento de un monarca en el exterior del templo ${ }^{16}$.

Tras el breve estudio de estas edificaciones podemos decir que frecuentemente en la creación de los ámbitos occidentales nos encontramos con distintas motivaciones meramente funcionales. Sin embargo se puede observar que prima en ellas el sentido funerario de un espacio eminentemente ligado al poder. Ello viene dado por tratarse de zonas situadas en las proximidades de la entrada del templo (que simboliza las Puertas del Paraíso) en las que todo fiel que se abriese paso hacia el interior de la iglesia observaría su enterramiento, siendo ello causa de gran satisfacción entre los altos estamentos de la sociedad. El enterramiento en la zona del pórtico irá perdiendo importancia con el devenir de los años, abriendo así paso al uso de la galilea como eminente lugar de enterramiento para los más privilegiados.

Analizando la planimetría, estamos ante una serie de ejemplos que presentan una morfología prerrománica (la cual en muchas ocasiones la podemos encontrar encubierta con un léxico ya románico). No obstante esta morfología de raigambre hispánica durante las últimas décadas del siglo XI convivirá con fórmulas que nos llegan a la Península directamente de Cluny.

Adentrándonos ya en el siglo XII, hemos de recordar que estamos en el momento en el que se vuelve a conquistar el interior de los templos para los enterramientos ${ }^{17}$. Debido a ello

14 Yepes, A., Crónica General de la Orden de San Benito, edic. de Fray Justo Pérez de Urbel, t. III, Madrid, 1960, p.57. Por otro lado, la referencia que de Ambrosio de Morales hace Yepes la podemos encontrar en esta misma obra, p. 56: "Están la sepultura de los infantes y de todos los infantes de Carrión, sus descendientes, en una pieza fuera de la iglesia, que ni es capilla ni tiene alta ni retablo, ya la llaman Galilea"

15 Sancho III introducirá los usos cluniacenses en el monasterio y a su muerte será aquí enterrado, al igual que sucederá con su hijo. De esta manera entroncan con la figura de Sancho García que en 1011 contribuyó a la fundación de este monasterio de monjas para que hiciese las veces de panteón regio. Este personaje sería enterrado en el pórtico junto con algunos de sus caballeros.

16 Aquí podemos ver claramente cómo va evolucionando la visión que de los ámbitos funerarios tenían las clases privilegiadas.

17 Un dato interesante es que tras la construcción del monasterio cluniacense de Alcobaça entre 1178 y 1252 , los reyes portugueses no consiguieron obtener el permiso para llevar a cabo sus enterramientos en el interior del templo. Debido a ello mandaron realizar un panteón en el pórtico occidental. 
podemos ver cómo se transforma tanto el interior como la planimetría de las iglesias en función de los nuevos ámbitos funerarios. No obstante estos nuevos proyectos intentan, siempre dentro de unas determinadas pautas, "colonizar" una serie de reducidos espacios dispuestos de manera regular y ordenada, articulándolos para ello con las naves y el presbiterio.

Pese a esta novedad podemos seguir encontrando ámbitos funerarios utilizados en la centuria anterior, tal es el caso de los pórticos (en los cuales la única diferencia en relación a los anteriores es el cambio del lenguaje formal). Éstos serán utilizados como ámbito funerario de los privilegiados durante el periodo intermedio comprendido entre la prohibición de realizar enterramientos en el interior de las iglesias, hasta su permisión.

Un caso excepcional será el del Monasterio de Las Huelgas en Burgos (fig. 9), que al estar dedicado al enterramiento de los miembros de la familia Real, los nobles van a tener que situar sus sepulturas en la parte exterior del conjunto monástico. La solución que se le da a esta cuestión es la adecuación de un prolongado pórtico lateral que contornea la fachada septentrional de la iglesia doblando todo alrededor del crucero ${ }^{18}$. Estos notables normalmente hacían colocar sus monumentos funerarios arrimados a los paramentos, aunque podemos encontrarnos también sepulcros que impiden el paso de los fieles.

A comienzos del siglo XII comienza la lucha de una serie de personajes para conseguir ubicar enterramientos en el interior del templo. En 1137 Alfonso VII intentaría que los cuerpos regios enterrados en el exterior fuesen trasladados al interior del templo. Dando así uno de los primeros pasos en la tentativa de conquistar el interior de las iglesias, aunque de una manera más teórica que práctica, puesto que aún se venían utilizando los ámbitos funerarios propios del siglo anterior.

Un ejemplo de ello, aunque bastante más temprano ya que se sitúa en la órbita del siglo XI, es el de Domingo Manso, personaje de gran autoridad y prestigio espiritual, y el Monasterio de San Sebastián de Silos. Tras la muerte de Domingo en 1073 es enterrado en el claustro del monasterio, ya que no se atreven a enterrarlo en el interior del templo ${ }^{19}$. Tres años después, tras ser beatificado, su cuerpo será trasladado al interior del templo, concretamente ante el altar de san Martín. Este dato nos lo aportará su biógrafo, Grimaldo. No obstante para el traslado de este cuerpo al interior se tuvieron que dar muestras de que se trataba ya del cuerpo de un santo $^{20}$. Con ello se pone de relieve que el enterramiento en el interior de las iglesias era algo excepcional, a lo que todavía no tenían acceso ni los más privilegiados $^{21}$.

Estamos pues ante un precedente bastante temprano en lo que toca a la conquista del interior de los templos.

18 Gómez Moreno, M., El Panteón real de las Huelgas de Burgos, Madrid, 1946, págs. 12-13.

Ejemplo de ello lo podemos ver también en el Monasterio cisterciense de San Andrés del Arroyo en Palencia. En su amplio pórtico lateral en el que unos epígrafes hacen referencia a las gestas de caballeros y muerte. Esto nos puede dar a entender que pueden estar allí enterrados. No obstante, se trata de un ejemplo bastante tardío para nuestro estudio, pero a su vez interesante, ya que este ámbito funerario sigue las pautas de Las Huelgas.

19 Vita Domini Silensis, de Grimaldo, Logroño, 1982, p. 308

20 Bango Torviso, I., "La iglesia antigua de Silos: Del prerrománico al románico pleno", en El románico en Silos. IX Centenario de la Consagración de la iglesia y claustro, Abadía de Silos, 1990, p. 327.

21 Pese a que existen ciertas noticias de enterramientos ante el altar mayor en determinados templos, como es el caso relatado por el Marqués de Viana aludiendo a Sancho Ramírez, no nos ofrecen gran credibilidad ni fiabilidad. (Orcastegui, C., La crónica los reyes de Navarra del Príncipe de Viana, Pamplona, 1978, p.127) 
Retomando la figura de Alfonso VII, según Ricardo del $\mathrm{Arco}^{22}$, a su muerte, acaecida en 1157, fue enterrado en la capilla mayor de la Catedral de Toledo. No obstante, si seguimos la "Crónica General" 23 podemos ver cómo se narra la conducción del cadáver a la Catedral de Toledo, pero no nos especifica si fue enterrado en la capilla mayor o cualquier otra capilla del templo toledano. Al año siguiente se enterrará en este mismo lugar a su hijo Sancho $\mathrm{III}^{24}$. En ninguna de las fuentes de la época se cita que fuese enterrado en la capilla mayor, sino que se refieren a una capilla concreta. Aquí se nos plantea una duda ante la falta de restos debido a las remodelaciones posteriores. Esta capilla ocuparía un ámbito cercano a la cabecera siguiendo un esquema similar a las capillas reales de la Catedrales de Sevilla y Córdoba, o bien siguiendo el modelo de la Catedral de Santiago de Compostela, situándose en el extremo del crucero $^{25}$. En esta última serían enterrados Fernando II en el año 1188, y posteriormente en el 1230 Alfonso IX. Pese a los documentos alusivos a este ámbito funerario apenas conocemos nada de él, ni siquiera cómo se aislaba de la nave del crucero.

Esta conquista del interior de los templos lleva implícita una jerarquización de los espacios, dando así mayor relevancia a unos espacios frente a otros, llegando a cobrar el emplazamiento más relevancia que la propia monumentalización del espacio y que el propio sepulcro. De los espacios más codiciados es el que se encuentra situado entre el coro y el Altar Mayor puesto que al estar allí emplazado se tenía la creencia que las oraciones y los cánticos de los fieles llevarían con mayor presteza a la Salvación al alma del difunto. Será este lugar el que ocupen, por ejemplo los cuerpos de los fundadores del Monasterio de las Huelgas $^{26}$.

A su vez de esta manera se rompe la focalidad del conjunto, ya que al situarse el monumento funerario en el centro del crucero o ante el altar mayor (en el presbiterio) corta la visión de la comunidad de fieles hacia el altar creando lo que se ha venido a llamar una "bipolaridad focal".

Otro caso de enterramiento privilegiado en el coro es el del Obispo Don Mauricio, el cual había emprendido la construcción de la Catedral gótica de Burgos. En esta ocasión no se trata de un cuerpo regio, pero es aquí enterrado, en 1238, por tratarse de un personaje que mantenía una especial relación con dicho templo.

Una vez conquistado el interior de los templos, la ambición y el deseo de prestigio llevan a buscar espacios propios donde poder ser enterrado, poniendo de esta manera un

22 Arco, R. del, Sepulcros de la casa Real de Castilla, Madrid, 1954, p. 209.

23 Crónica General, p.661

24 Idem. P. 667

25 Según Ambrosio de Morales "Los reyes que están enterrados en esta santa Iglesia tuvieron Capilla en el Crucero al lado del Evangelio. Detrás la puerta alta del Crucero sale á las casas del Arzobispo, mas porque ocupaba y afeaba allí la iglesia, y tampoco era un lugar muy honroso. El emperador que está en el cielo dio licencia que se pasasen á la Capilla del Cabildo, que se llama agora de los Reyes"

26 Aquí trasladados desde su ubicación original. Un acta notarial de la documentación del monasterio de las Huelgas recoge un hecho muy curioso en el que intervienen los deudos del infante Don Pedro y la abadesa, en agosto de 1319. éste quería enterrarse en lugar de privilegio, restando así protagonismo a los sepulcros de Leonor y Alfonso VIII, y rompiendo también la estructura bipolar del Altar Mayor. La abadesa concedería provisionalmente el permiso a este enterramiento, que más tarde sería llevado a un lugar secundario en las naves, recuperando de esta manera el esquema interno del templo. Gómez Moreno, M., op. Cit, pp. 34-35. 
mayor énfasis en la importancia del linaje. De esta manera surgen las capillas funerarias propiamente dichas. En ese afán de preeminencia los notables buscarán colocar su capilla en una parte bien visible del templo, rompiendo de esta manera la planimetría del mismo.

Los edificios románicos carecían de espacios que pudiesen ser destinados a la creación de capillas privadas, por lo que bien se creaban de nueva planta, o bien para su ubicación recurrían a ocupar partes del templo que carecían en principio de funcionalidad funeraria. Entre estos espacios podemos encontrar torres y criptas de evidente función tectónica. No obstante no debemos confundir este tipo de criptas, que poseen una función estructural, con las criptas situadas bajo panteones y mausoleos, ya que estas últimas se usan de manera complementaria de estos ámbitos (para contener, normalmente, los ataúdes). Un bello ejemplo de la reutilización de estas criptas tectónicas lo encontramos en la iglesia de San Lorenzo de Carboeiro (Pontevedra) (Fig. 10), realizada ya en el siglo XII.

A lo largo del recorrido a través de estos siglos hemos podido ver en qué manera ha ido evolucionando el ámbito funerario de los privilegiados, aunque nunca perdiendo de vista ese afán de protagonismo, de notoriedad y de "ser vistos" por los fieles que acuden al templo.

Otro punto interesante es que realmente en la mayor parte de las ocasiones es el emplazamiento, no las tumbas o sarcófagos, el que se convierte en el símbolo de una familia y la expresión de su linaje. Es debido a ello por lo que se otorga tanta importancia en encontrar un ámbito preeminente en el que ser enterrado, ya que el lugar escogido para ello denota claramente la posición social y el poder del personaje. Otra cuestión muy ligada al emplazamiento será la religiosa, puesto que se tenía la idea de que si estaba situado a la puerta del templo se encontraba metafóricamente en la Puertas del Paraíso, o bien, si se situaba en el coro, los cántico y oraciones de la comunidad religiosa y los fieles elevarían más rápidamente el alma del difunto hacia el Paraíso,...

A lo largo de estos siglos hemos podido observar una especie de devenir cíclico en esta evolución, ya que tras la prohibición de enterrar los cuerpos en el interior de las iglesias se pasa a un momento en el que los enterramientos notables, a diferencia del resto, se ubicaban en lugares próximos al interior, tal es el caso de pórticos, galileas... Siendo estas últimas un lugar escogido principalmente para enterramientos regios. Para a partir de ahí volver, poco a poco, a introducir los enterramientos (en su mayor parte regios) en el interior de los templos. Para ello se realizarán importantes cambios planimétricos en los templos que alterarán el esquema primigenio de las construcciones prerrománicas y románicas.

Toda esa creación de ámbitos funerarios para personajes privilegiados desembocará en la creación de importantes y paradigmáticas obras, que incidirán en el desarrollo y cambio de las tipologías templarias a lo largo de la Historia.

\section{BIBLIOGRAFÍA:}

ARCO, R. DEL, Sepulcros de la casa Real de Castilla, Madrid, 1954.

BANGO TORVISO, I., El arte románico en Castilla y León, Banco de Santander D. L, Madrid, 1997.

BANGO TORVISO, I., "El espacio para enterramientos privilegiados en la arquitectura medieval española", Anuario del Departamento de Historia y Teoría del Arte 4 (1992). 
BANGO TORVISO, I., "Arte prerrománico hispano. El arte en la España cristiana de los siglos VI al XI”, en Summa Artis. Historia General del Arte, vol. VIII-II, Madrid, 2001.

DÍAZ JIMÉNEZ, J., "San Isidoro de León”, Boletín de la Sociedad Española de Excursiones, Madrid, 1997.

DURLIAT, M., Espagne Romane, Paris 1993.

GALTIER F., "Le corps occidental des églises dans l'art roman espagnol du XI siecle: problèmes de recepción d'un modèle septentrional", CCM, XXXIV, (1991).

GÓMEZ MORENO, M., El Panteón real de las Huelgas de Burgos, Madrid, 1946.

GÓMEZ MOREnO, M., Catálogo monumental de España. Provincia de León, Madrid, 1925.

GRIMALDO, Vita Domini Silensis, Logroño, 1982.

ORCASTEGUI, C., La crónica los reyes de Navarra del Príncipe de Viana, Pamplona, 1978.

SENRA,J.L, “Aproximación a los espacios litúrgico-funerarios en Castilla y León: pórticos y Galileas”, Gesta, XXXVI/2 (1997).

YEPES,A., Crónica General de la Orden de San Benito, edic. de Fray Justo Pérez de Urbel, t. III, Madrid, 1960. 


\section{ANEXOS IMÁGENES}

Fig. 1 Planta del Panteón Real y restos de la Iglesia (izquierda) y Planta actual con el Panteón ante la fachada occidental de la iglesia (derecha)
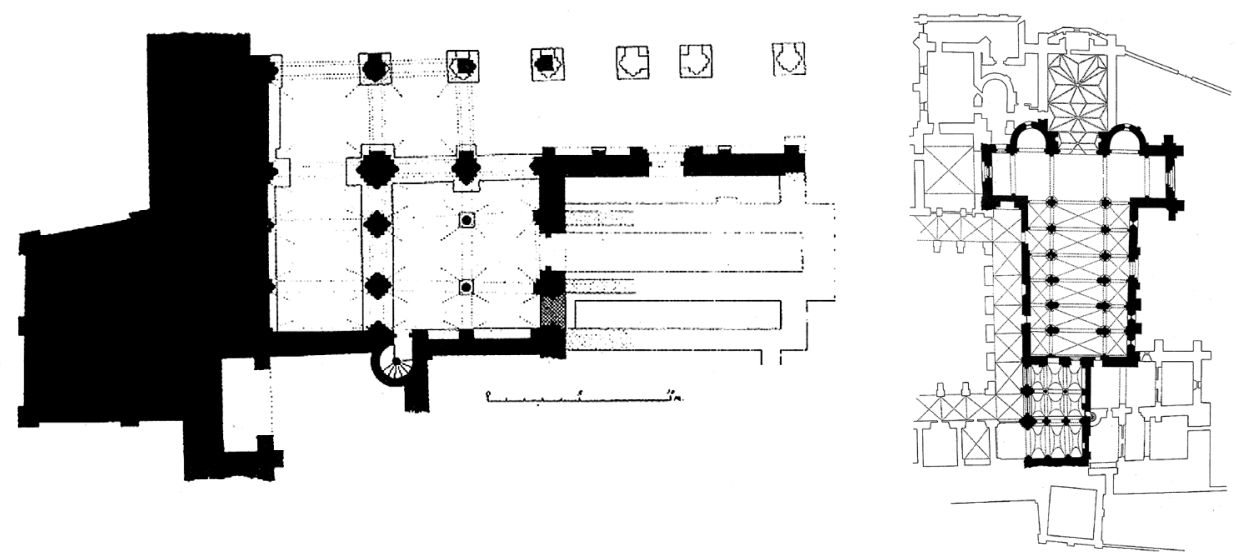

Fig. 2. Planta de San Pedro de Teverga

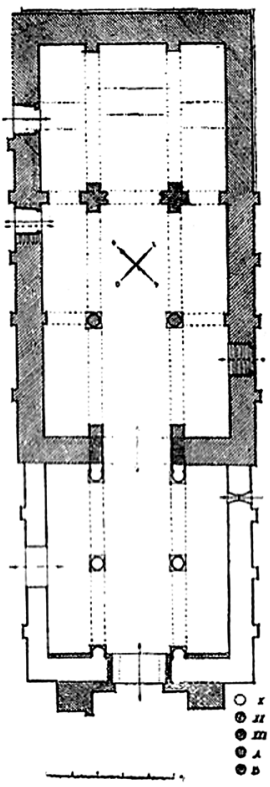


Fig. 3 Comparación entre el Panteón de San Isidoro (izquierda) y la planta del pórtico de Teverga (derecha)
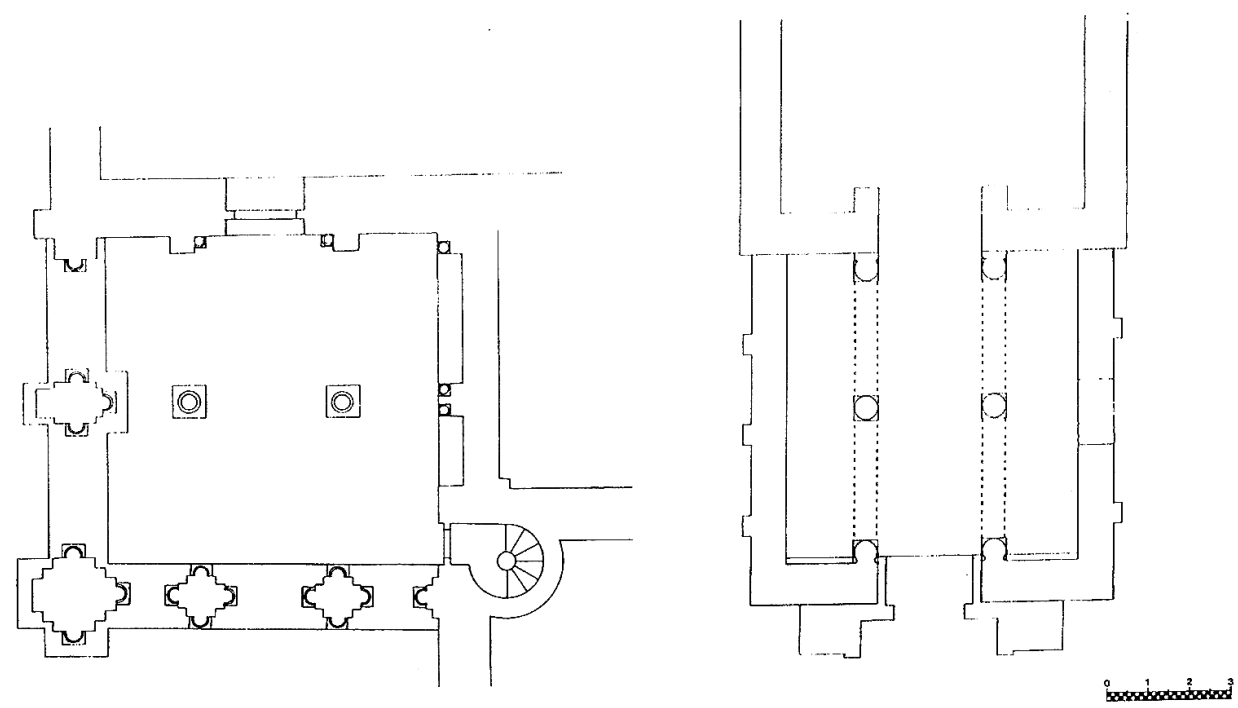

Fig. 4. Iglesia y Panteón real, construcción prerrománica (I. Bango)

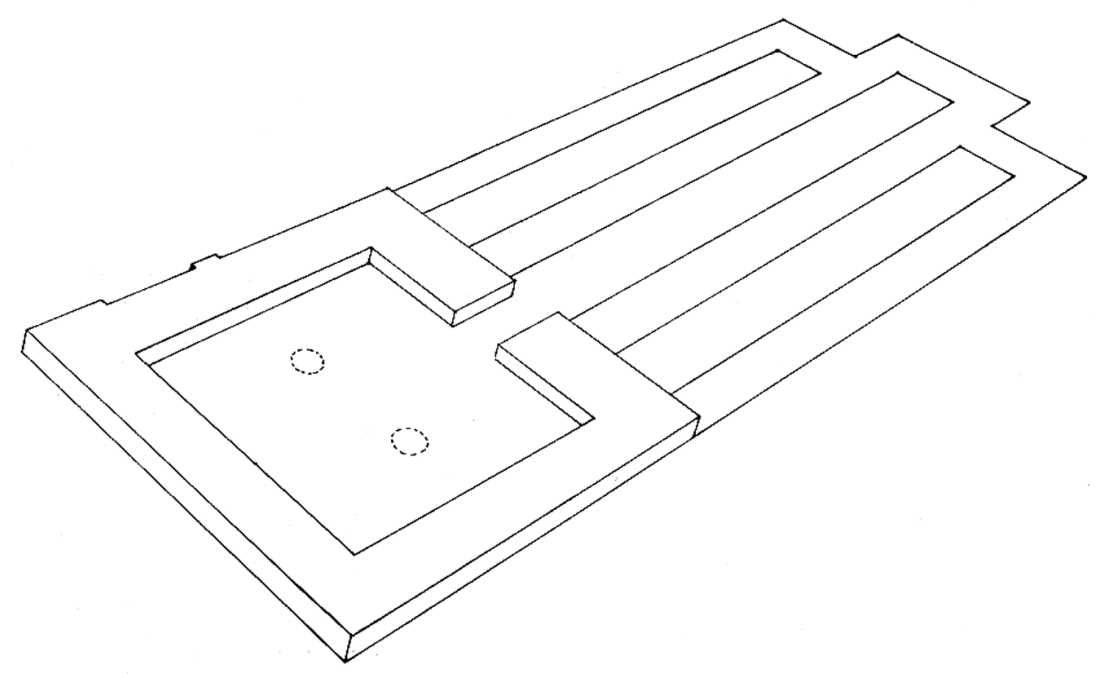


Fig. 5. Iglesia y Panteón real, transformación románica. En esta imagen podemos observar el cambio de léxico llevado a cabo tras la remodelación. (I. Bango)

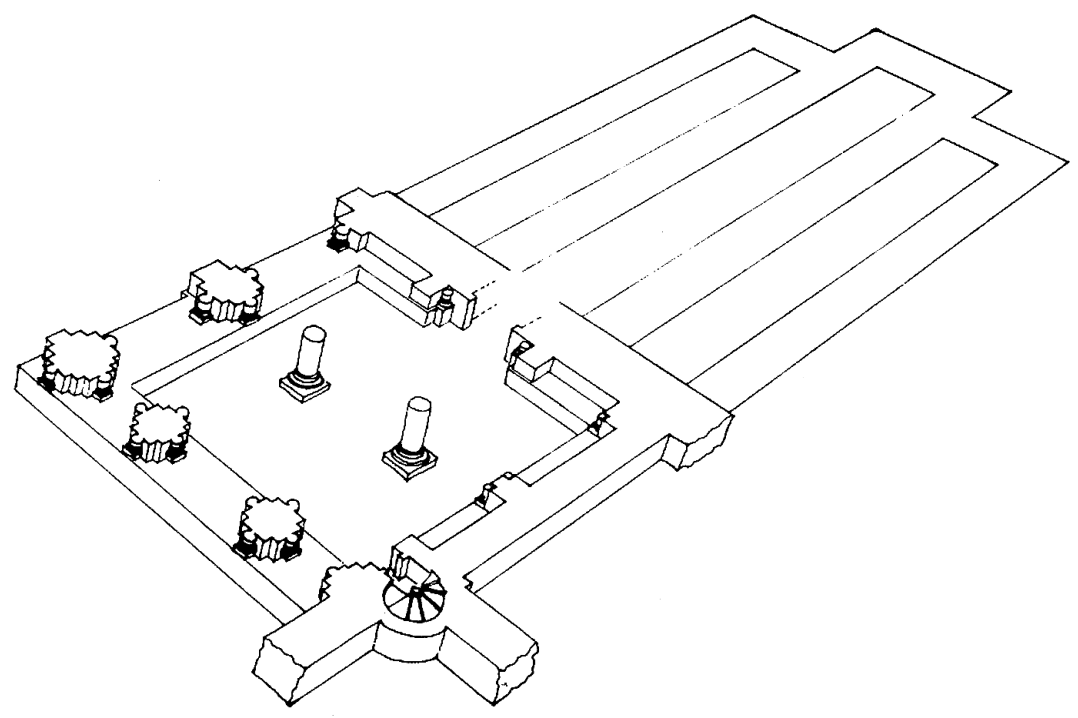

Fig. 6. Capilla de San Mancio. Monasterio de Sahagún

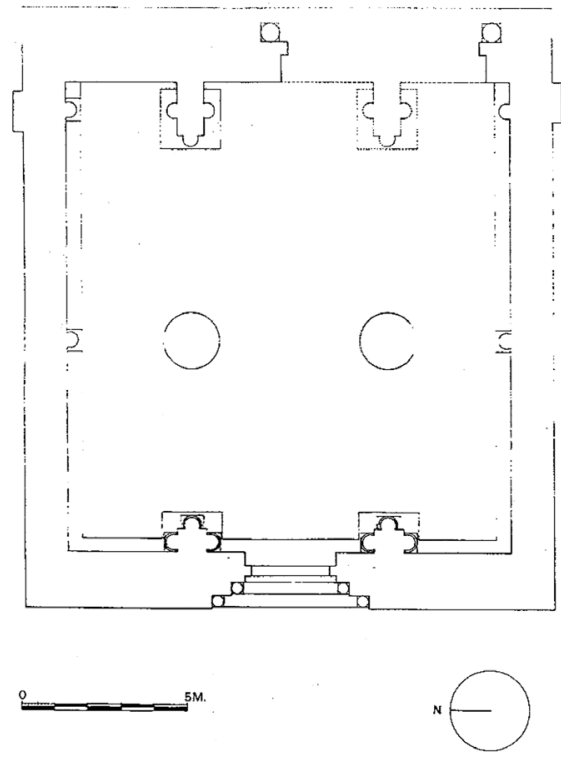


Fig. 7. Plano del Monasterio de San Zoilo de Carrión

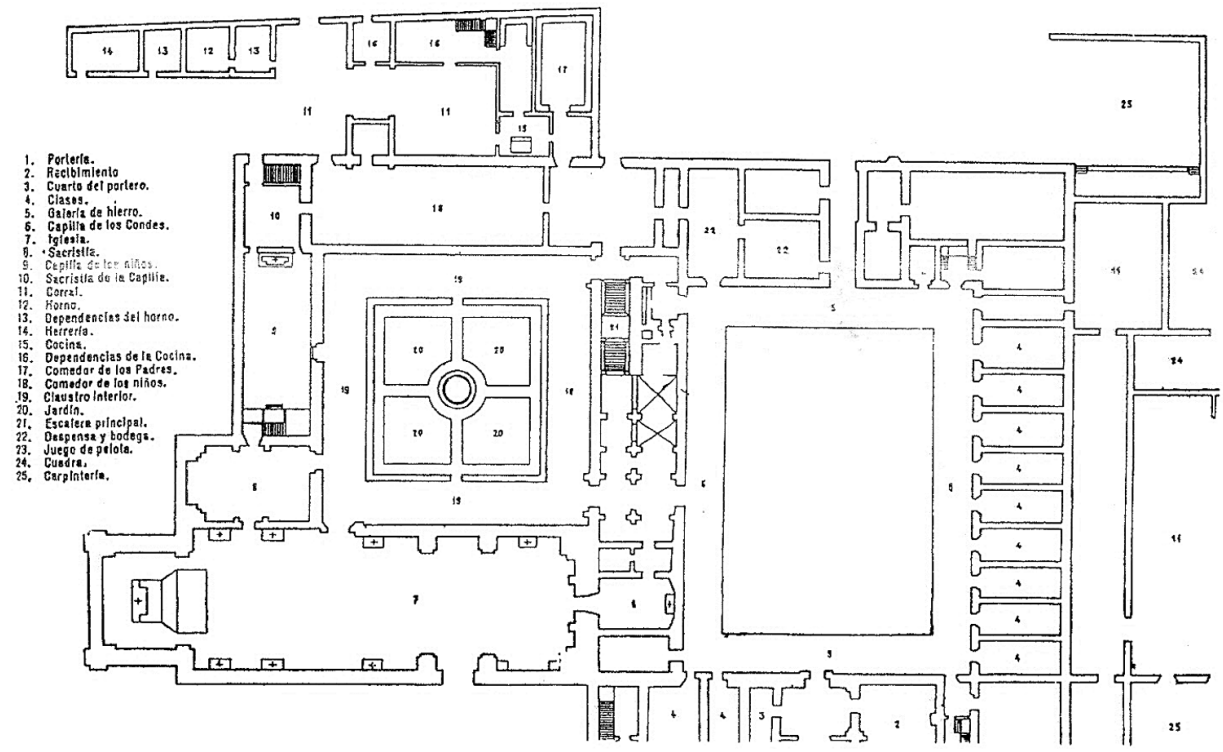

Fig. 8. Planta hipotética de la iglesia tardorrománica del Monasterio de Sahagún con la ubicación de la Capilla de San Mancio.

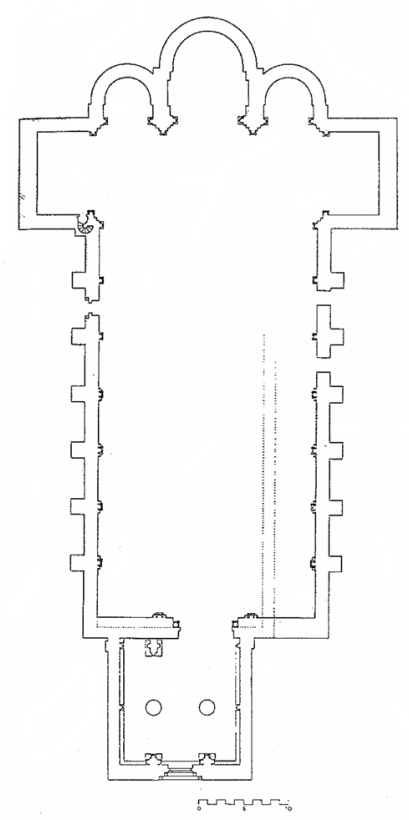


Fig. 9. Plano del Monasterio de las Huelgas

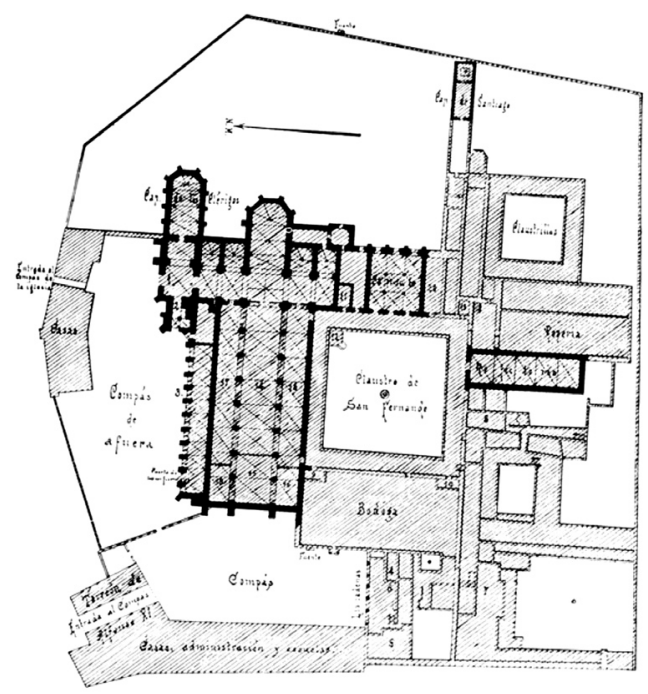

Fig. 10. Sección de la cabecera de San Lorenzo de Carboeiro en la que podemos ver en la parte baja la estructura de la cripta.

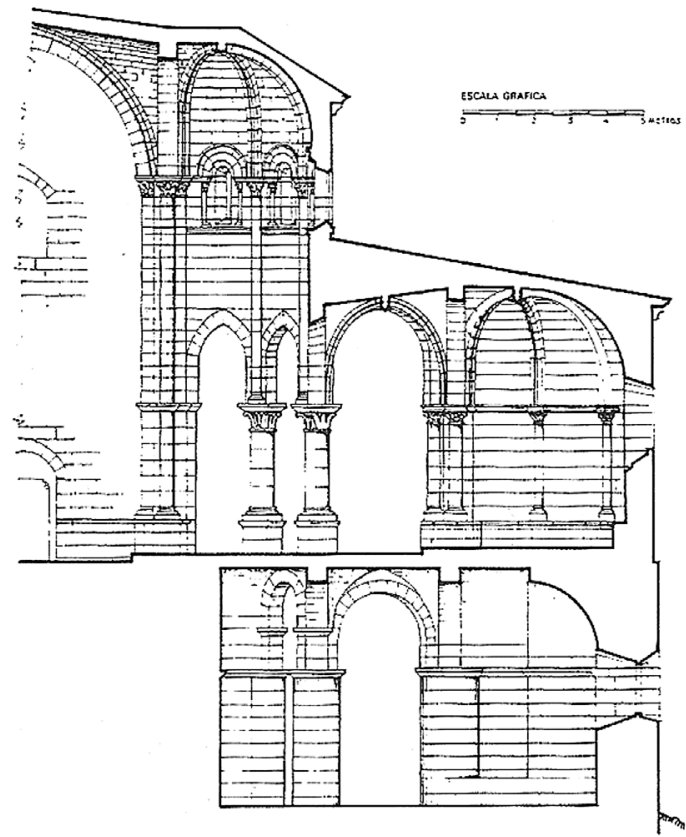

